\title{
DINÂMICA TERRITORIAL E A ESTRUTURAÇÃO ESPACIAL DO ESTADO DO RIO DE JANEIRO
}

\author{
CLAUDIO ANTONIO GONÇALVES EGLER ${ }^{1}$ \\ MARCOS THIMOTEO DOMINGUEZ ${ }^{2}$ \\ ANDRÉ NEUSCHWANG REGATO ${ }^{3}$
}

\section{Resumo}

No presente trabalho, a dinâmica territorial e seus rebatimentos na organização regional do estado do Rio de Janeiro serão analisados a partir dos conceitos de policentralidade e coesão territorial. Por intermédio de uma visão multiescalar e do mapeamento de fluxos entre cidades, são discutidas as transformações e os processos espaciais que contribuem para a diferenciação interna do território fluminense. Essa distinção é fundamental para se pensar programas governamentais de desenvolvimento regional, para identificar novos arranjos urbanos e para propor novas perspectivas a respeito da estruturação espacial de políticas públicas e de ações estratégicas de caráter territorial.

Palavras-chaves: policentralidade, coesão territorial, dinâmicas territoriais e Rio de Janeiro Territorial dyanamics and spatial structure of the State of Rio de Janeiro

\begin{abstract}
In the present work, the territorial dynamics and their effects in the regional organization of the State of Rio de Janeiro will be analyzed from the concepts of policentralidade and territorial cohesion. By means a vision multierscalar and mapping of flows between cities, are discussed the transformations and the spatial processes that contribute to the internal differentiation of the territory. This distinction is essential to think about government programs of regional development, to identify new arrangements and to propose new perspectives regarding the spatial structuring of public policies and strategic actions of territorial nature.
\end{abstract}

Keywords: polycentricity, territorial cohesion, territorial dynamics and Rio de Janeiro

\section{INTRODUÇÃO}

O território é a manifestação e o espaço mais evidente dos processos econômicos, sociais e políticos que moldam as regiões a partir das experiências de vida da população e das interrelações entre lugares (EGLER et al., 2013). Considerá-lo dentro do debate sobre políticas regionais desvela não apenas os limites do nosso sistema de desenvolvimento, mas também as contradições que se estabelecem entre sociedade e Estado.

Nesse entendimento, o expressivo processo de urbanização do país e o fortalecimento das funções urbanas, as mudanças no interior dos processos produtivos, o papel dos meios de transportes e de comunicações e a revolução científica e tecnológica são constatações que revelam o surgimento de novas formas de organização socioespacial e que impõem uma revisão do real alcance das respostas por parte das políticas públicas e programas governamentais.

O Estado do Rio de Janeiro (ERJ), unidade federativa com um dos maiores percentuais de urbanização e concentração demográfica do país, vem passando por processos acelerados em termos de reestruturação espacial de suas áreas urbanas. Como consequência, há a intensificação das disparidades socioeconômicas entre municípios, com especial destaque para aqueles da Região Metropolitana (RMRJ) e, também, desses quando comparados às demais regiões do estado. Essa realidade demanda

1 Geógrafo e Doutor em Economia - UFRJ. cegler@gmail.com

2 Cientista Social e Doutorando em História - FGV. marcosthdz@yahoo.com.br

3 Geógrafo e Assessor de Planejamento - sEPLAG. andreregato@planejamento.rj.gov.br 
um esforço de complementaridade não apenas de atividades econômicas e das políticas sociais, mas também entre territórios, sejam eles considerados urbanos ou rurais.

$\mathrm{Na}$ verdade, como vem sendo debatido nas últimas décadas, a urbanização das cidades promove-se a partir do processo de circulação de capital e não se dá apenas pela produção (sANTos, 2007). A ampliação dos serviços, da informação e da terceirização das relações de trabalho produzem valor e novas formas de acumulação de capital (HARVEY, 2012). O surgimento dessa perspectiva e a formação de novos arranjos institucionais e territoriais constituem-se, também, em evidências que forçam o poder público e outros agentes econômicos a reverem o formato de seus projetos e ações estratégicas de caráter territorial.

A atuação governamental tanto do Governo do Estado como das prefeituras fluminenses deve assumir como agenda de trabalho comum o aumento da integração entre as regiões de modo a identificar demandas prioritárias, resultantes do conjunto de arranjos institucional entre cidades de forma a potencializar a produção e a enfrentar históricos problemas sociais e ambientais.

Para caminhar na direção proposta, partiremos da definição de dois conceitos estratégicos para o desenvolvimento regional do ERJ: a coesão territorial e a policentralidade. A noção de coesão territorial parte do princípio de que os agentes sociais que atuam em determinado território podem colaborar em torno de programas e projetos comuns, reduzindo os custos de transação inerentes ao processo de desenvolvimento (EGLER et al., 2013). Do ponto de vista da coesão territorial, o Rio de Janeiro, embora seja uma das áreas mais dinâmicas do Brasil tem ainda um território desarticulado com manifestações de injustiça social e distribuição desigual de impactos ambientais (PORTO, 2007).

A complementaridade deve se apoiar na ideia de policentralidade entre municípios e regiões, já que os territórios são lugares onde se estruturam redes de distintas escalas de articulação. A policentralidade é um conceito associado à ideia de rede de cidades, segundo a qual os núcleos urbanos formam nós que são conectados por arcos ou eixos (EGLER et al., 2013), por onde circulam fluxos materiais e informações. O esforço a policentralidade no território fluminense contribui para gerar coesão territorial com uma maior participação das instituições públicas, de agentes econômicos e da sociedade no processo de desenvolvimento regional, descentralizando atividades econômicas, principalmente na zona costeira fluminense, e aumentando as possibilidades de acesso a bens e serviços qualificados no interior do estado.

Não se trata de traçar metas simples de gestão, deve-se alcançar um novo pensamento cívico, amparado por exercícios reflexivos que têm no território a ponta de lança de um conjunto de ações e programas estratégicos capazes de dialogar com as diferentes escalas de interação humana e de enfrentar as carências históricas do desenvolvimento desigual e periférico. Neste sentido é que se entende o território como fator estruturador de políticas, uma vez que é nele que a população vivencia as mudanças econômicas e sociais. A partir dessa abordagem, busca-se a construção de um sistema de valores de forma a embasar as práticas públicas, capacitando-as a enfrentar a complexidade intra e interregionais que hoje se configura no estado do Rio de Janeiro.

\section{DINÂMICA TERRITORIAL DO ESTADO DO RIO DE JANEIRO}

Os territórios moldados pelo processo de urbanização apresentam novas configurações espaciais que se diferenciam de pretéritas formas de uso e ocupação da terra. Por isso é preciso entender o espaço urbano como suporte ao desenvolvimento econômico e social, onde diferenciações e desigualdades podem revelar potencialidades ou obstáculos à integração territorial. A dinâmica demográfica, por exemplo, responde a fenômenos espaciais distintos, que servem de base conceitual para a atuação dos setores públicos, especialmente aqueles que atuam na área ambiental e na de infraestrutura urbana. Reflexos das relações econômicas e sociais, o crescimento demográfico e o acelerado adensamento urbano nos municípios fluminenses possuem a capacidade de gerar efeitos e demandas em relação às políticas de mobilidade urbana, saneamento e habitação (OBSERVATóRIO DAS METRÓPOLES, 2009).

A característica demográfica do ERJ, hoje, atende por uma Região Metropolitana (RMRJ) que concentra $70 \%$ dos habitantes, conferindo desequilíbrio à relação trabalho/estudo/moradia entre os municípios das periferias metropolitanas e a capital, de forma que o estado responde por três dos cinco 
maiores deslocamentos pendulares do Brasil (IBGE, 2015). O Rio de Janeiro segue a tendência nacional que aponta para a redução das taxas de crescimento demográfico nas áreas urbanas centrais. Contudo, dados apontam para certo dinamismo demográfico em cidades com população superior a 100 mil habitantes, com destaque para cidades que se encontram fora da Região Metropolitana (SANTOS, 2012).

Além da estrutura regional centrada na Região Metropolitana, o ERJ tem uma ocupação costeira de maior densidade e dinamismo econômico, que se estende para as Regiões de Governo da Baixada Litorânea, Norte e da Costa Verde ${ }^{4}$, que acabam por funcionar como um vetor de esgarçamento da malha urbana ao longo dos eixos rodoviários que percorrem o litoral: BR-101 sentido Sul (Rio-Santos) e sentido Norte (direção a Campos) e RJ-106, que interliga as Regiões dos Lagos e Norte, via o conjunto de cidades Rio das Ostras/Macaé.

A instalação da Petrobras em Macaé, por exemplo, gerou importantes transformações econômicas no litoral Norte que se estende, hoje, das baixadas litorâneas até o limite do estado com o Espírito Santo; o parque industrial e siderúrgico do Médio Paraíba, por sua vez, alongou o eixo produtivo automobilístico e metal/mecânico, percorrendo a BR-116 (Rodovia Dutra) em direção a São Paulo; a indústria de petroquímicos na Região Metropolitana, que visa a incorporar as atividades produtivas da Refinaria de Duque de Caxias (REDUC) ao Complexo Petroquímico (COMPERJ), em Itaboraí; e o setor naval em Angra dos Reis são exemplos de empreendimentos e cadeias industriais e logísticas que ocasionaram uma mudança no padrão de urbanização e crescimento populacional fluminense.

A presença de parques industriais e novos empreendimentos de grande porte nesses municípios indicam certa dispersão das atividades industriais do estado nos últimos anos (sANTOS, 2012), ainda altamente concentradas na cidade do Rio de Janeiro. As transformações territoriais ocasionadas por essas mudanças acabam por gerar concentrações urbanas em localidades anteriormente isoladas, criando assim conjuntos de municípios e eixos de desenvolvimento que não podem mais ser compreendidos separadamente. A oferta de serviços públicos e a construção de políticas urbanas devem ser pensadas a partir desses agregados municipais e regionais, a exemplo de Macaé/Rio das Ostras; Maricá/Itaboraí na RMRj; e Barra Mansa/Volta Redonda no Médio Paraíba.

O Estado precisa compreender em suas ações essas novas estruturas espaciais, da mesma forma que é preciso rever a antiga ideia de polos econômicos, que considerava que o crescimento econômico em um único município o elevava ao posto de centralidade o que, por si só, seria capaz de transbordar sua economia para o entorno imediato. Na verdade, na ausência de coesão territorial, uma cidade-polo avança carregando consigo uma periferia formada por municípios menos dinâmicos que, por falta de planejamento e integração a uma cadeia produtiva bem estruturada, ficam expostos a uma precária oferta de serviços e com uma economia altamente vulnerável às oscilações nos setores econômicas das áreas centrais.

Nesse sentido, tanto os empreendimentos nas cidades intermediárias como a concentração de grande volume de serviços e recursos econômicos na RMRJ não lograrão na tarefa de integrar municípios e regiões caso a visão sobre o desenvolvimento continue amparada sobre estruturas territoriais nucleadas e/ou fragmentadas. O resultado desse desequilíbrio será a manutenção da forte pressão demográfica e o avanço da mancha urbana sobre áreas ambientais e terras sem regularização fundiária estabelecida.

Esse quadro impacta as administrações municipais, que na ausência de fôlego orçamentário e de planejamento não conseguem organizar seus instrumentos legais de gestão e de ordenamento do solo. Na relação entre centralidade e desenvolvimento econômico, a desigualdade na distribuição de equipamentos e serviços urbanos acaba por gerar barreiras à inclusão social por parte de grande parcela da população que, sem alternativas, embarca nas atividades produtivas de baixa qualificação geralmente expostas a maiores desgastes físicos e emocionais, longo tempo e desconforto nos deslocamentos intermunicipais.

Uma forma de compreensão desse processo pode ser extraída a partir da interpretação dos dados

4 O Estado do Rio de Janeiro possui ao todo oito regiões de governo em sua regionalização oficial: Metropolitana, Costa Verde, Médio Paraíba, Centro Sul Fluminense, Serrana, Baixadas Litorâneas, Norte Fluminense e Noroeste Fluminense. 
referentes aos movimentos pendulares e ao incremento demográfico dos municípios ao longo dos últimos anos. O Mapa o1, referente a deslocamento populacional intercidades para fins de trabalho, aponta que alguns municípios intermediários em termos de população possuem maior capacidade de atração do que outros, evidenciando estruturas econômicas e espaciais distintas.

Mapa 01: deslocamento intermunicipal para fins de trabalho no ERJ

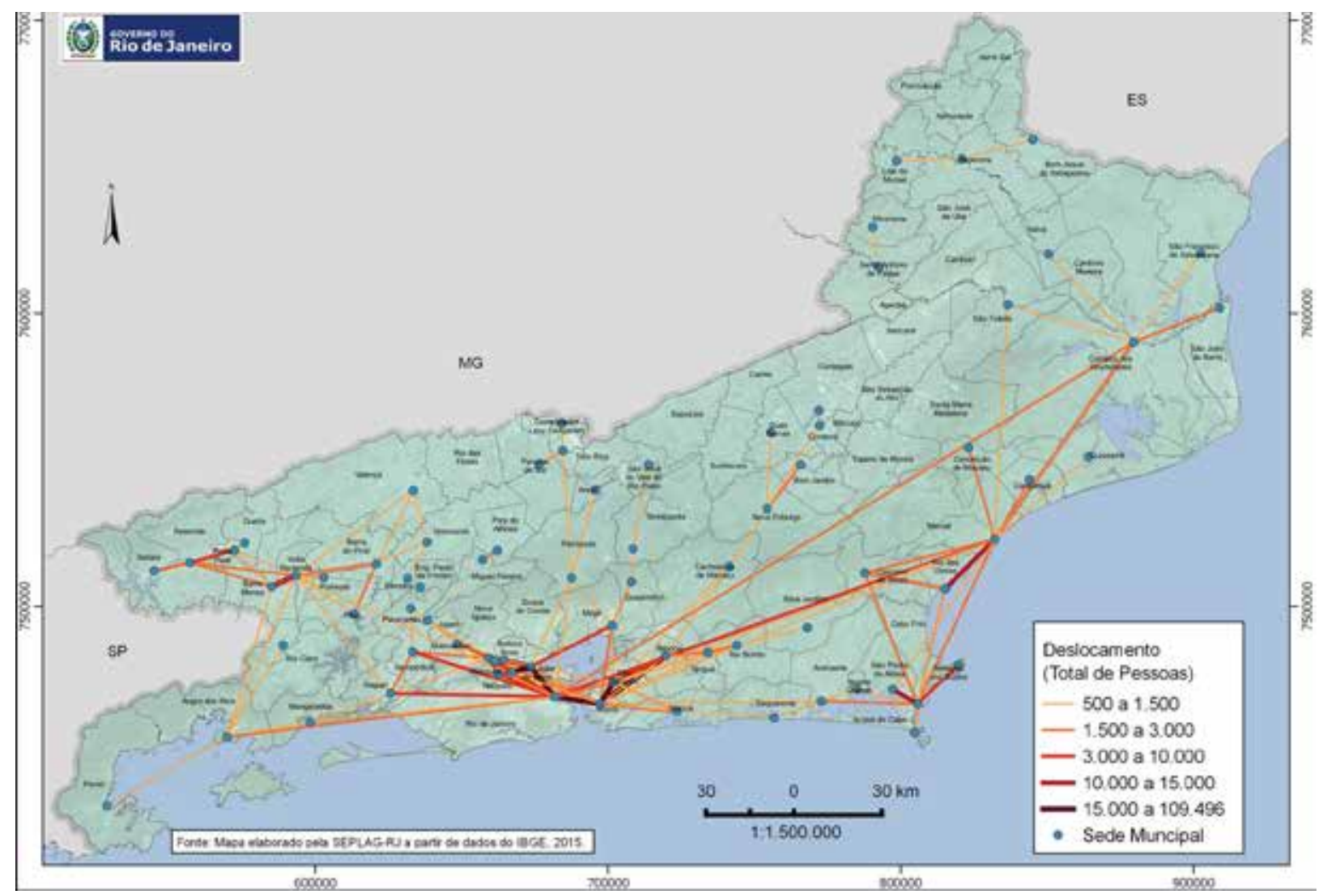

Ao analisar os dados de deslocamento fora da RMRJ ficam evidentes as diferenças em termos de atração por um "polo" regional. Enquanto o município de Macaé, na região Norte, atrai aproximadamente 45 mil pessoas para fins de trabalho e estudo, na região Serrana, Nova Friburgo, Petrópolis e Teresópolis juntos não alcançam 30 mil movimentos diários (IBGE, 2015). Por outro lado, o eixo Volta Redonda e Barra Mansa, na região do Médio Paraíba, compartilha um fluxo aproximado de 20 mil pessoas, dinamismo este traduzidos em números de deslocamento superiores aos relativos a Cabo Frio, importante município das Baixadas Litorâneas, cuja população alcança aproximadamente 187 mil habitantes e com uma taxa de crescimento anual de $3,9 \%$ na década (Tabela o1).

É preciso considerar, também, que há cidades, que mesmo com um porte populacional acima de 100 mil habitantes não podem ser consideradas como centralidades regionais. De acordo com a Tabela 01, Rio das Ostras possui a maior taxa de crescimento anual do estado nos últimos anos, atrai cerca de 8.500 pessoas diariamente, principalmente de municípios vizinhos, como Casimiro de Abreu. Contudo, mais de 12 mil habitantes deixam Rio das Ostras em direção a Macaé em busca de oportunidades de emprego. Da mesma forma, na outra ponta costeira, Angra dos Reis, que também cresceu a taxas elevadas e cuja população chegou a 170 mil moradores, em 2010, vem sofrendo com uma conformação urbana precária em termos de serviços de infraestrutura, com uma taxa de $35 \%$ de domicílios localizados em aglomerados subnormais (IBGE, 2010). Crescendo de maneira acelerada, $3,5 \%$ ao ano, a cidade recebe cerca de nove mil pessoas por dia, oriundas de diversas localidades, caracterizando deslocamentos pulverizados, sem um padrão de atração bem definido. 
Tabela 01: Municípios com população superior a 100 mil habitantes fora da RMRJ

\begin{tabular}{|c|c|c|c|c|c|c|c|}
\hline \multirow[t]{2}{*}{ Municípios } & \multirow[t]{2}{*}{ Regiões de Governo } & \multicolumn{2}{|c|}{ População } & \multicolumn{2}{|c|}{ Urbanização (\%) } & \multicolumn{2}{|c|}{ Taxa de crescimento anual } \\
\hline & & 2000 & 2010 & 2000 & 2010 & 2000 & 2010 \\
\hline Campos dos Goytacazes & Norte & 406.989 & 463.731 & 89,5 & 90,3 & 0,88 & 1,31 \\
\hline Petrópolis & Serrana & 286.537 & 295.917 & 94,5 & 95,1 & 1,3 & 0,32 \\
\hline Volta Redonda & Médio Paraíba & 242.063 & 257.803 & 100 & 100 & 1,06 & 0,63 \\
\hline Macaé & Norte & 132.461 & 206.728 & 95,1 & 98,1 & 3,96 & 4,55 \\
\hline Cabo Frio & Baixadas Litorâneas & 126.828 & 186.227 & 83,8 & 75,4 & 5,86 & 3,92 \\
\hline Nova Friburgo & Serrana & 173.418 & 182.082 & 87,6 & 87,5 & 0,42 & 0,49 \\
\hline Barra Mansa & Médio Paraíba & 170.753 & 177.813 & 96,7 & 99,1 & 0,49 & 0,41 \\
\hline Angra dos Reis & Costa Verde & 119.247 & 169.511 & 95,9 & 96,3 & 3,79 & 3,58 \\
\hline Teresópolis & Serrana & 138.081 & 163.746 & 83,4 & 89,3 & 1,52 & 1,72 \\
\hline Resende & Médio Paraíba & 104.549 & 119.769 & 91,8 & 93,8 & 2,56 & 1,37 \\
\hline Araruama & Baixadas Litorâneas & 82.803 & 112.008 & 90,7 & 95,1 & 3,87 & 3,07 \\
\hline Rio das Ostras & Baixadas Litorâneas & 36.419 & 105.676 & 94,9 & 94,5 & 8,09 & 11,24 \\
\hline
\end{tabular}

Fonte: IBGE, 2010

Esses distintos fenômenos espaciais baseiam-se em fluxos de pessoas que respondem a relações desiguais entre municípios e regiões. A atuação pública deve apoiar-se sobre essa perspectiva, inclusive com revisões a respeito das regionalizações de governo. Ao buscar a coesão entre territórios, a Administração necessita partir do princípio de que os agentes políticos devem atuar em determinados territórios de forma colaborativa em torno de programas e projetos comuns (EGLER et al., 2013). Mais do que polos regionais e novas centralidades, conceitos que acabaram por isolar lugares um dos outros, é preciso construir "cidades compartilhadas", ou seja, Áreas Urbanas Integradas (AUI), capazes de gerar policentralidades, porém, pautadas em valores como complementaridade e sustentabilidade.

A partir desse ponto, construir uma visão estratégica territorial envolve mais do que a implementação de empreendimentos estruturantes ou políticas setoriais. Uma ação territorial estratégica precisa ter a capacidade de interligar tanto o atendimento a demandas específicas como também contribuir para a efetivação de políticas estruturantes para a integração territorial. Devem estar associadas ao campo da infraestrutura urbana e da logística, porém ser pensadas a partir de uma visão ampla de território, de forma a superar os limites da fragmentação espacial e excessiva setorização pública. O planejamento territorial pauta-se, então, nas dinâmicas regionais, problematizando os entraves a serem enfrentados.

\section{AÇÕES ESTRATÉGICAS DE INTEGRAÇÃO TERRITORIAL}

A título de organização metodológica serão apresentados a seguir três conjuntos integrados de ações estratégicas territoriais amplamente debatidos tanto em fóruns especializados quanto no âmbito da esfera pública fluminense, e que devem ser pensados a partir dos conceitos de policentralidade e de coesão social:

1. Políticas de infraestrutura urbana, envolvendo os setores de saneamento, habitação e transporte público por considerar que essas áreas se retroalimentam, através de um esforço conjunto de organização e ordenamento urbano e da provisão de serviços coletivos básicos à reprodução social da população;

2. Economia regional, destacando a capacidade de promoção da integração territorial através da interligação entre empreendimentos de grande porte a partir de eixos logísticos e da promoção de cadeias produtivas já existentes para o impulso das economias regionais;

3. Sistemas de Informação Espacial, que articulam produção de informação em diferentes áreas e escalas, ao mesmo tempo em que servem de ferramenta e subsídio para a efetivação dos demais conjuntos de ações. 


\section{Infraestrutura urbana}

O ERJ possui uma taxa de urbanização de 97\%, de acordo com o IBGE (Censo de 2010). Conforme já mencionado, o processo de urbanização responde a diferentes estímulos, dependendo da região e do município analisado. A tendência metropolitana é de espraiamento de sua mancha urbana, que segue em direção às periferias e a antigas zonas rurais nos limites da metrópole (LAGO, 2012). Além disso, os municípios metropolitanos que apresentam taxas elevadas de incremento populacional, como Guapimirim e Maricá, vêm sofrendo com a pressão demográfica sobre seus bens ambientais, o que merece ser alvo de atenção por parte do poder público estadual e dos órgãos de fiscalização. As políticas urbanas devem ir ao encontro desses fenômenos, porém, não apenas combatê-los, mas compreender que dinâmicas territoriais os alimentam. É nesse sentido que o campo da infraestrutura deve ser pensado por setores que se complementam.

Uma recente avaliação do Programa Minha Casa, Minha Vida (MCMv) realizada pelo Instituto de Pesquisa e Planejamento Urbano e Regional (IPPUR/UFRJ), que analisou os empreendimentos com obras iniciadas e implantados até 2012 na RMRJ (OBSERVATÓRIO DAS METRÓPOLES, 2015), identificou na relação entre os setores da área habitacional, de saneamento e de transporte, nos diferentes níveis de governo, certo descompasso no que tange às ações de infraestrutura básica para a efetiva realização do programa.

O PMCMV, além de prover a construção de unidades habitacionais, tem como meta servir de impulso para a coesão territorial dos municípios metropolitanos, de modo que antigos modelos de políticas habitacionais sejam superados por moradias populares integradas à cidade e aos seus serviços. $\mathrm{O}$ Governo do Estado tem como meta ampliá-lo na Região Metropolitana, zona de maior déficit habitacional. Contudo, deve observar os pontos de desencontro que limitam a atuação dos órgãos setoriais das prefeituras municipais.

Como ação estratégica territorial, o PMCMV precisa ser implementado em parceria com os setores de saneamento e mobilidade urbana, disponibilizando numa mesma mesa de tomada de decisões grupos técnicos e instituições da sociedade. Com isso, é necessário que se tenha melhores diagnósticos territoriais, orientando as aplicações de recursos e a atuação nos municípios e agentes de mercado.

Mapa 02: cobertura da rede geral de esgoto nos municípios do ERJ

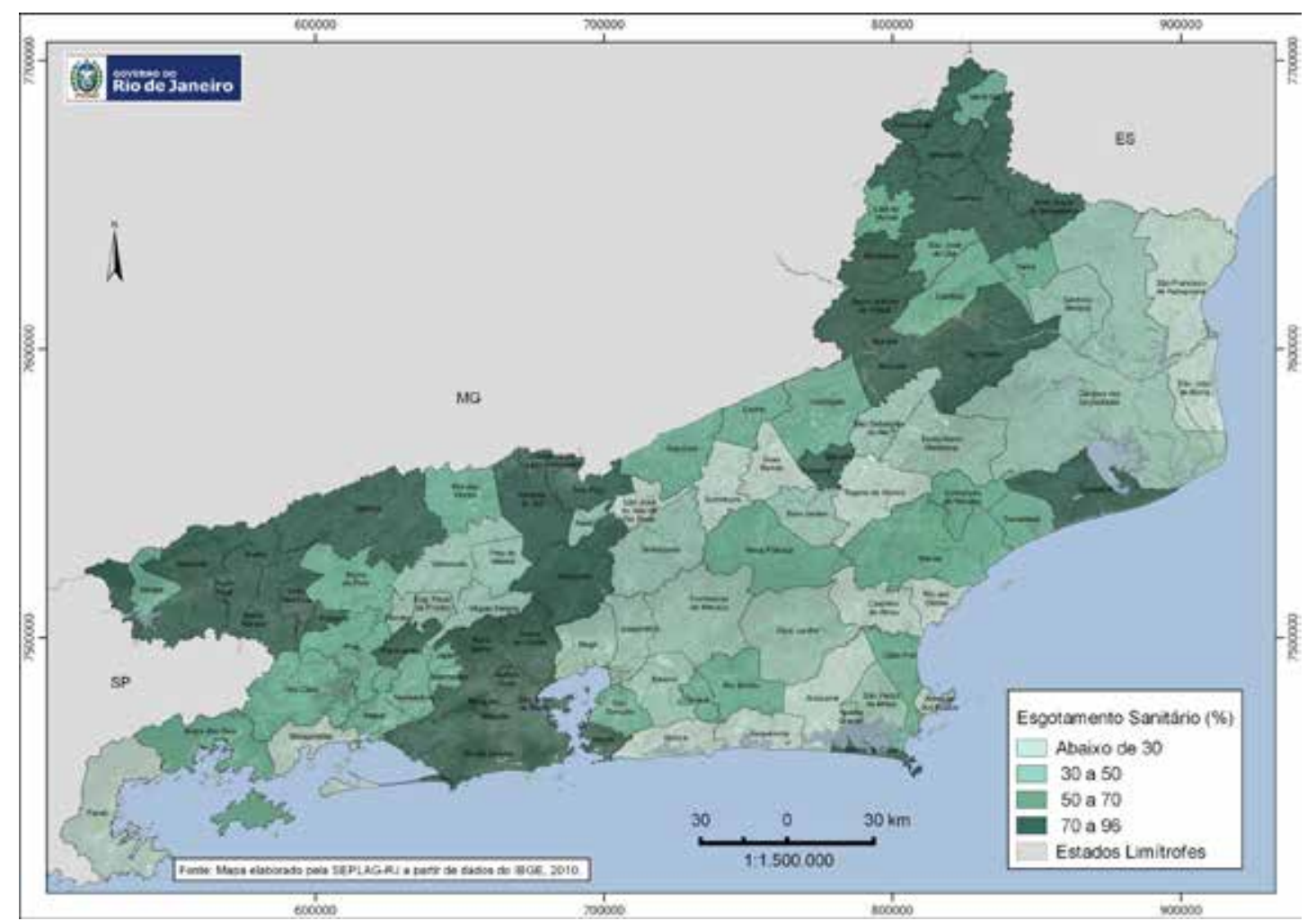


O Mapa 02, produzido pela Secretaria de Estado de Planejamento e Gestão do RJ (SEPLAG), relativo à presença de rede geral de esgoto nos domicílios de cada município fluminense em 2010, por exemplo, deixa clara a desigualdade de cobertura desse sistema nas cidades. Analisando a distribuição espacial, é possível notar que os piores indicadores se estendem do leste da Baía de Guanabara, na RMRJ, e seguem na direção da região Norte, justamente da faixa territorial com maior crescimento demográfico nos últimos anos.

A demanda por moradia, além do passivo histórico da periferia metropolitana, vem ocorrendo no eixo leste-norte fluminense, que segue pela BR-101. O município de São Gonçalo, por exemplo, com a segunda maior população do estado, possui um das piores coberturas de saneamento da Região Metropolitana. Assim, para que o PMCMv tenha seu objetivo concretizado, é fundamental que os programas de saneamento no entorno da Baía de Guanabara obtenham êxito na sua efetivação nos próximos anos.

Está em andamento a execução do Programa de Saneamento Ambiental dos Municípios do Entorno da Baia de Guanabara (PSAM), da Secretaria de Estado do Ambiente (sEA), que prevê, entre outras ações, a construção do sistema de esgotamento sanitário em São Gonçalo, de forma a superar o antigo problema estrutural que dificulta o ordenamento territorial desse município e acaba funcionando como obstáculo à plena ação de programas e projetos voltados para seu desenvolvimento social e econômico. Espera-se que essas iniciativas se consolidem e mantenham certa coerência e continuidade em sua execução, diferentementemente de períodos passados, quando prevaleceram a ruptura do planejamento territorial e a descontinuidade de programas.

Além de projetos da área de saneamento e habitação, a integração e ampliação da malha viária do estado assume papel central para a conquista de equilíbrio regional. Indiscutivelmente, a RMRJ ganhou foco nos últimos anos por conta da instalação do COMPERJ, que hoje vive um momento de incerteza em termos de funcionamento e capacidade produtiva. Seu anúncio acarretou num fator de atração de investimentos e pessoas que automaticamente aumentou a demanda por bens e serviços, principalmente, de infraestrutura urbana. Consequência ou não, o Leste Fluminense responde pelo maior deslocamento populacional do estado, com 200 mil pessoas/dia que se deslocam entre os municípios de Itaboraí, São Gonçalo e Niterói (IBGE, 2015).

No caso da mobilidade urbana, também há importantes dinâmicas demográficas para além da Região Metropolitana e que também merecem ser alvo de atenção. O mapa dos deslocamentos populacionais apontou o conjunto municipal Rio das Ostras/Macaé como importante arranjo produtivo e de troca de serviços. Considerando os dados do IBGE, aproximadamente 20 mil pessoas seguem de Cabo Frio, de Casimiro de Abreu e de Rio das Ostras diariamente em direção a Macaé, principalmente pela Rodovia Amaral Peixoto (RJ-106), gerando forte congestionamento na via e ampliando gravemente o tempo de viagem e demais problemas de ordem social e ambiental vinculados a esse fenômeno pendular.

A noção de policentralidade pode ser compreendida pelo seguinte exemplo: com a ampliação do eixo RJ-106 e aumento da circulação de pessoas e bens, e considerando a já existente consolidação de Macaé como centralidade regional, o município Rio das Ostras, que possui uma Zona Espacial de Negócios (ZEN) localizada à margem da rodovia Amaral Peixoto, tem a oportunidade de ampliar sua oferta de serviços e de logística para o mercado, atendendo assim tanto as empresas já instaladas no polo vizinho como diversificando internamente sua própria economia. Assim, a formação de uma AUI permitirá a possibilidade de elevação da arrecadação tributária em toda a região do entorno de Macaé, reduzindo o grau de dependência financeira dos municípios e gerando maior autonomia na definição de suas políticas prioritárias e investimentos.

\section{O papel da logística para a economia regional}

As ações estruturantes de logística devem ter como meta fundamental garantir a circulação de mercadorias, informação e pessoas. Conforme defendeu Milton Santos, em vez da produção garantir a circulação, como funcionavam as relações antes da revolução tecnológica informacional, hoje, a circulação é a garantia para a realização da produção (sANTOS, 2007). O desenvolvimento da economia regional depende de fluxos e movimentos, principalmente em regiões e cidades com pouca presença de plantas industriais, baixa urbanização e falta de um mercado de serviços complexos. 
Com uma concentração produtiva no litoral, a cadeia logística estadual deveria ter como objetivo alavancar a economia interiorana, agregando-a a atividades dinâmicas dos principais centros, contribuindo para promoção de suas economias e relações de trabalho. O setor agropecuário, que se estende principalmente da Região Serrana até o Noroeste Fluminense pode se beneficiar de estratégias de integração, sendo incorporado aos setores produtivos da faixa litorânea. Na realidade, o campo logístico é o responsável pelo equilíbrio na relação entre o atender e o promover a economia de cidades e regiões.

É fundamental que a estrutura logística de carga, abastecimento e distribuição, por exemplo, atenda às atividades agrícolas dos municípios do Noroeste Fluminense, principalmente aqueles ao longo do eixo da BR-393/RJ-186, que interliga o Médio Paraíba à região Norte, percorrendo entre ambos as regiões de governo Centro-Sul Fluminense e Serrana. No Mapa O3, desenvolvido pela SEPLAG-RJ, é possível identificar a posição estratégica do eixo logístico em questão, que além de conectar regiões separadas física e economicamente, permite maior troca comercial entre municípios, e destes com os estados de São Paulo, através de seu encontro com a BR-116, Minas Gerais e Espírito Santo.

Mapa 03: eixos logísticos do Estado do Rio de Janeiro

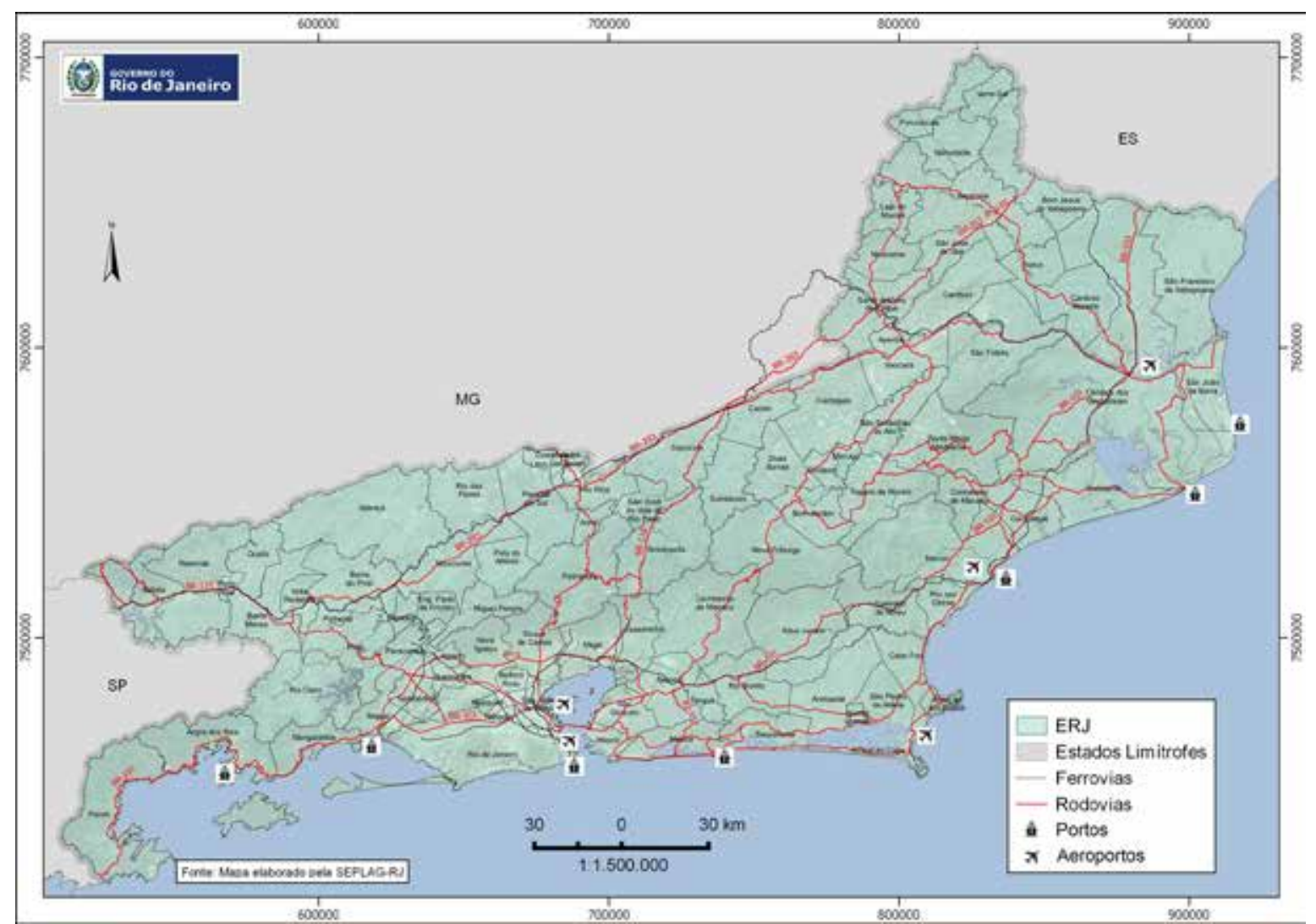

Essa análise se justifica, pois é muito comum avaliar o desempenho das atividades econômicas a partir do peso de cada setor no pIB estadual. Contudo, tal indicador é insuficiente para pensar as economias regionais e o grau de integração entre lugares. Os municípios do Noroeste Fluminense, da Região Centro-Sul e parte da Região Serrana são exemplos de que as dinâmicas territoriais não enfrentam processos homogêneos de urbanização e de fluxos intercidades. Municípios que não apresentam as mesmas características das áreas urbanas integradas, ou seja, que possuem uma estruturação espacial fragmentada em meio à extensão rural e a ambientes ecológicos de preservação, precisam ser tratados com certo cuidado no âmbito do debate sobre coesão territorial e sustentabilidade.

No caso do PIB, o setor agropecuário fluminense, quando comparado aos setores industriais e de serviços, mostra-se praticamente inexpressivo. Porém, para as economias locais, essa atividade pode 
alcançar até 30\% do PIB municipal, a exemplo de Sumidouro, na Região Serrana (CEPERJ, 2015). Além disso, é fator essencial para subsistência e manutenção das relações produtivas, históricas e culturais, o que garante uma base mínima de qualidade de vida à população.

A cadeia logística nesse ponto favorece a ampliação dessas atividades, permitindo inclusive que a agricultura familiar, característica em nosso estado (sANTOs, 2012), e os pequenos empreendimentos de extração mineral, muito presente nas regiões em debate, ganhem em competitividade tanto nos principais mercados do ERJ, quanto da própria região Sudeste.

O eixo logístico BR-393/RJ-186 permitirá que os conjuntos de municípios Valença/Rio das Flores/Três Rios/Areal, Itaocara/Aperibé/ Santo Antonio de Pádua e Itaperuna/Bom Jesus do Itabapoana passem a ocupar um agregado espacial estratégico para o equilíbrio da economia regional, que mesmo distante dos números das atividades industriais e empreendimentos costeiros, ganharão em coesão territorial, favorecendo a distribuição de serviços e a sustentabilidade dos ambientes e territórios.

Outra questão a ser levantada refere-se ao papel chave que a logística tem para a promoção das economias regionais, a partir da integração entre municípios, projetos empresariais e mercados. A integração territorial tem na infraestrutura logística de carga seu condicionante fundamental, requerendo recuperação e ampliação da rede ferroviária, articulação entre as redes viárias, federal, estadual e municipal e melhoria dos acessos complementares aos portos e aeroportos.

Em termos regionais, a implementação de um terminal portuário por si só não resolve os gargalos de infraestrutura industrial e produtiva. Pelo contrário, gera fortes impactos sociais e ambientais tanto em escala local como regional. Há a necessidade de criação de arcos e eixos de conexão planejados para sua alimentação, fomentando desta forma o surgimento e consolidação de cadeias produtivas. Para a construção de uma coesão territorial sustentável, a partir da estrutura e do conceito de policentralidade, o ERJ tem hoje importantes desafios.

Após a construção do Porto do Açú, em São João da Barra; do inicio das obras do Comperj, em Itaboraí; e do Terminal Portuário de Ponta Negra, em Maricá (previsto), o tema da logística é inseparável da necessidade da integração territorial dos municípios e regiões. Como colocado anteriormente, a presença de um empreendimento de grande porte numa região do estado, transformando cidades em novos polos econômicos, pode gerar centralização de atividades, aumento dos deslocamentos intermunicipais, incremento demográfico e, consequentemente, problemas socioambientais e maiores demandas por serviços.

Dessa forma, antigas propostas ganham novas formatações ao apontar como prioridades o Corredor Logístico do Açu, a finalização do Arco Metropolitano e a ampliação e revitalização das Ferrovias EF-118 (RJ-ES) e Ferrovia EF-354 (GO-RJ), presentes no Plano Estadual de Logística (PELC). Trata-se da possibilidade para que esses empreendimentos se consolidem não apenas como ações estratégicas para os mercados nacional e internacional, mas como projetos estruturantes básicos para a configuração de uma rede policêntrica fluminense, integrada internamente e aberta para trocas comerciais e produtivas com outros estados do Brasil.

$\mathrm{Na}$ RMRJ, o Arco Metropolitano surge como vetor de complementariedade espacial. Mais do que simplesmente contribuir para o transporte de cargas e produtos entre o Comperj/Terminal Portuário de Maricá e os terminais da Bacia de Sepetiba (Itaguaí) e Angra dos Reis, na Costa Verde, o corredor viário assume hoje fundamental posição para que toda a Região Metropolitana se articule de maneira a ampliar projetos urbanos e desenvolver novas tecnologias e conhecimento científico. Mesmo diante das incertezas do Comperj, o Arco gera novas perspectivas sobre o processo de ocupação metropolitano, onde cidades como Magé e Guapimirim, antes municípios dormitórios, por exemplo, agora se aproximam de áreas urbanas mais estruturadas em termos de produção, trabalho e serviços, possibilitando novas trocas e tendo a oportunidade de serem incorporadas a cadeias produtivas mais complexas.

Por fim todas essas ações estratégicas territoriais se amparam na formação de áreas urbanas integradas, com a consolidação de pares ou mais agregados de municípios articulados, seja por, conta da ampliação e diversificação da infraestrutura urbana, seja por meio da conexão logística que atende às economias regionais. Enquanto no primeiro caso impulsiona importantes políticas de caráter estritamente urbano, no segundo é fundamental para a coesão territorial pela promoção de projetos estruturantes, interligando-os na direção da sustentabilidade e da policentralidade como fatores de desenvolvimento regional. 


\section{Sistemas de informação espacial e a análise multiescalar do território}

O terceiro conjunto de ações estratégicas na verdade é subsídio para a construção transparente e sólida de um planejamento territorial estruturado a partir da transversalidade entre políticas. As administrações estadual e municipal produzem uma série de informações relativas ao território que costumam ser interpretadas ou por uma abordagem de escala única ou pela visão setorial fragmentada. Dificilmente há uma conciliação entre a produção de informação, a construção de políticas e a análise conjunta do espaço.

O resultado é a constatação de um ambiente tecnológico amplo, porém não interligado e de uma multiplicidade de sistemas promissores, mas que acabam por ter sua funcionalidade interrompida ou até mesmo defasada. Considerando que os sistemas são instrumentos que potencializam o acesso a dados e às informações geográficas, hoje elemento imprescindível para a gestão estratégica pública e privada, é preciso considerá-los e utilizá-los como mecanismos de interface entre as áreas de conhecimento técnico e o processo de consolidação da transparência pública.

A ideia defendida até o momento - incorpora noções de coesão territorial e policentralidade, e de práticas efetivas descritas por uma série de ações estratégicas territoriais - é reforçada pela necessidade de serem acompanhadas e internalizadas por esses sistemas. Os sistemas de informação espacial são fundamentais à produção de projetos técnicos e diagnósticos socioespacial e ambiental de cidades e regiões, assim como para o acompanhamento sistemático de programas prioritários e identificação de problemas estruturais.

As possibilidades abertas partem desde a integração de instrumentos como os planos setoriais e regionais, os planos diretores, os zoneamentos econômicos e ecológicos até a criação de metodologias de análise dos fenômenos espaciais e urbanos. O desenho das ações territoriais estratégicas como base da criação de áreas urbanas integradas, passa diretamente pelo conhecimento do território. Esse olhar, no entanto, deve estar atento ao movimento entre escalas, já que as relações socioespaciais ocorrem em diferentes níveis de complexidade.

É preciso entender que a tomada de decisão em torno de um empreendimento como o terminal portuário ou um parque industrial, por exemplo, envolve grandes corporações, governos federal, estadual e municipal, instituições de mercado, grupos organizados da sociedade civil e inúmeros conflitos. É fundamental o poder público ser capaz de dialogar com esses agentes por meio de uma visão multiescalar. Além disso, a informação territorial se relaciona diretamente com a necessidade de as prefeituras projetarem seus ordenamentos urbanos. Hoje em dia não é possível a administração municipal produzir instrumentos e legislações de uso e ocupação do solo sem ter em mãos um grupo de mecanismos administrativos e tecnológicos que incorpore bancos de dados e sistemas geográficos de informação.

No caso da RMRJ, há uma proposta por parte do governo estadual de elaboração de um Sistema de Informação Metropolitana (SIM), que tem como objetivo oferecer às prefeituras, técnicos estaduais e à sociedade em geral um panorama das principais funções públicas de interesse comum da metrópole. Entre as ações, está prevista a construção de uma base cartográfica que servirá de base para o recadastramento de propriedades em áreas urbanas da metrópole e para a instrumentalização do ordenamento territorial dos municípios.

Para as demais regiões do estado, a SEA, conveniada com O IBGE, contratou a produção de ortofotos de alta resolução que, além de servir de base para o Zoneamento Econômico-Ecológico (ZEE) do estado, vem sendo utilizada para a construção do Cadastro Ambiental Rural (CAR), que passou a ser obrigatório em cumprimento ao Decreto Estadual no $44.512 / 13$ e responde às novas exigências do Código Florestal (2011) brasileiro.

Ainda na área ambiental, é importante ressaltar os sistemas de informação em saneamento, que se tornaram exigência legal a partir da sanção da Lei do Saneamento (Lei Federal no 11.445, 05/01/2007) e que precisam constar nos planos municipais de saneamento e planos regionais integrados. Sendo assim, tanto o SIM como o PSAM necessitam incorporar em suas atividades, além das bases cartográficas, um banco de dados com informações ambientais, econômicas e sociais produzidas nos diferentes níveis de governo e territórios. Não se pode pensar saneamento, por exemplo, em escalas e recortes que não respeitem as bacias hidrográficas. Nesse sentido, as políticas de saneamento devem 
contemplar os atributos das regiões hidrográficas, em detrimento dos recortes locais, utilizando no escopo de trabalho escalas que deem conta da complexidade do tema.

A complexidade em torno dos sistemas de informação espacial exige um conjunto de indicadores que tratam de diferentes temas e lugares para que seja possível utilizá-los na formulação de políticas públicas concretas e na aproximação com as diferentes regionalizações. $\mathrm{O}$ uso dessa tecnologia precisa ser disponibilizado às prefeituras, que por sua vez poderão desenvolvê-la e adequá-la às suas demandas principais. Essa ação garante segurança técnica e legal aos projetos de ordenamento municipal e à elaboração dos planos diretores.

Pelo exposto, pode-se verificar que a tarefa em buscar a coesão territorial das regiões do estado, estabelecida sobre uma estrutura policentrada, tem a seu alcance um instrumental tecnológico e informacional capaz de reduzir custos e agrupar iniciativas numa mesma direção. O conhecimento das demandas territoriais depende desse conjunto de sistemas e informações, o que exige um trabalho de articulação entre os níveis de produção de dados e suas formas de uso. Afinal, o território se organiza por processos econômicos, sociais e espaciais complexos, as relações não são homogêneas, e a atuação do estado não deve se apoiar numa visão cujos recortes territoriais sejam focalizados ou extraídos de cenários superficiais e apenas sintéticos.

\section{CONSIDERAÇÕES FINAIS}

O trabalho em questão apresentou temáticas relativas à integração territorial das regiões fluminenses e à criação de áreas urbanas integradas como um arranjo espacial e institucional em substituição ao modelo de polos regionais, baseado na centralidade de alguns municípios, o que acaba por gerar periferias socioambientalmente vulneráveis.

Como foi visto ao longo do texto, há processos em áreas urbanas fragmentadas que possuem dinâmicas socioeconômicas distintas das zonas urbanas consolidadas e, neste caso, precisam ser compreendidos e assistidos por ações capazes de minimizar os obstáculos à coesão e impulsionar as oportunidades existentes. As cidades são o local da reprodução social e das relações econômicas que dependem diretamente da presença de políticas e serviços públicos de qualidade. Dessa forma, o espaço urbano não apenas fornece esses elementos, mas determina a forma como eles serão ofertados e espacializados (MARICATO, 2013).

A partir dos conceitos de policentralidade e de coesão territorial, debateu-se a complementariedade entre territórios de forma a produzir espaços integrados nas regiões do Estado do Rio de Janeiro. A abordagem aqui orientada identificou programas e projetos previstos ou em andamento pela administração pública com potencial para fomentar o desenvolvimento regional pautado numa estrutura policentrada e pensada a partir de sua capacidade de compartilhamento de recursos, serviços e economias.

Além disso, os setores de infraestrutura urbana, economia regional e sistemas de informação espacial são campos que compartilham de um mesmo propósito: buscar a coesão territorial de forma a oferecer à população um conjunto de serviços públicos capaz de promover o encontro entre lugares de forma equitativa e sustentável e fomentar e ampliar a transparência e o acesso à informação.

As análises de hoje, então, devem fugir da tendência de reproduzir interpretações que costumam padronizar lugares, como se os mesmos funcionassem por meio de fenômenos bem definidos territorialmente. É papel do Estado, através do permanente diálogo com a sociedade, elaborar iniciativas para atender importantes demandas territoriais e promover novas oportunidades produtivas. Amparado numa visão territorial complexa e multiescalar, o ciclo de governo tem como tarefa articular as diferentes políticas públicas, que mesmo desenhados separadamente possuem como fator de conexão o seu papel estruturante.

\section{REFERÊNCIA BIBLIOGRÁFICA}

EGLER, Claudio et al. Pensar o território e a região: por uma agenda de desenvolvimento regional.

Mercator, Fortaleza, v. 12, n. 28, p.7-17, mai./ago. 2013;

CEPERJ. PIB Municipal, 2015. Disponível em: www.ceperj.rj.gov.br. Acessado em 01/o7/2015; 
HARVEY, David. Direito à Cidade. Lutas Sociais, São Paulo, n.29, p.73-89, jul./dez. 2012;

IBGE. Censo Demográfico 2010. Disponível em: www.ibge.ogov.br. Acessado em o1/o7/2015;

IBGE. Arranjos Populacionais, 2015. Disponível em: www.ibge.gov.br. Acessado em o1/o7/2015;

LAGO, Luciana. A Periferia Metropolitana como lugar do trabalho: da cidade-dormitório à cidade plena. In: Lago, Luciana (Org.). Olhares sobre a metrópole do Rio de Janeiro: economia, sociedade e território. Rio de Janeiro: Letra Capital: Observatório das Metrópoles: IPPUR/UFRJ: FASE, 2010. p. 175-190;

MARICATO, Ermínia. É a questão urbana, estúpido! In: Maricato et al. (Org). Cidades Rebeldes. São Paulo: Boitempo, 2013;

OBSERVATÓRIO DAS METRÓPOLES. Hierarquização e identificação dos espaços urbanos. Coleção Conjuntura Urbana. Letra Capital/Observatório das Metrópoles, Rio de Janeiro, 2009; OBSERVATÓRIO DAS METRÓPOLES. Avaliação do Programa Minha Casa Minha Vida na Região Metropolitana do Rio de Janeiro: Impactos Urbanos e Sociais, 2015, Instituto de Pesquisa e Planejamento Urbano e Regional/UfRJ, 2015;

PORTO, Marcelo. Uma ecologia política dos riscos: princípios para integrarmos o local e o global na promoção da saúde e da justiça ambiental. Rio de Janeiro: Editora Fiocruz, 2012;

SANTOS, Angela. Cidades Médias: novas fronteiras de oportunidades. In: Santos et al. (org). Rio de Janeiro: um território em mutação. Rio de Janeiro: GRAMMA: FAPERJ, 2012;

SANTOS, Milton. Encontros. Rio de Janeiro: Beco do Azougue, 2007. 